9 McCreadie RG. Diet, smoking and cardiovascular risk in people with schizophrenia. Descriptive study. $\mathrm{Br}$

original papers

J Psychiatry 2003; 183: 534 -9.
10 Thakore JH. Metabolic syndrome and schizophrenia. BrJ Psychiatry 2005: 186: 455-6.

11 Haddad PM. Antipsychotics and diabetes: review of nonprospective data. BrJ Psychiatry 2004; 184 (suppl 47): s80-6.

12 LambertT, Chapman L. Diabetes, psychotic disorders and antipsychotic therapy: a consensus statement. Med J Aust 2004; 181: 544-8.

13 Petty RG. Prolactin and antipsychotic medications: mechanism of action. Schizophr Res 1999; 35 (suppl 1): 67-73.

14 Holt RIG. The medical causes and consequences of

hyperprolactinaemia. A context for psychiatrists. J Psychopharmacol 2008; 22 (suppl 2): 28-37.

15 Berner MM, Hagen M, Kriston L. Management of sexual dysfunction due to antipsychotic drug therapy. Cochrane Database Syst Rev 2007; Issue 3: CD003546.

16 Herxheimer A, Healy D. Arrhythmias and sudden death in patients taking antipsychotic drugs. BMJ 2002; 325: 1253-4.

17 RayWA, Meador KG.

Antipsychotics and sudden death: is thioridazine the only bad actor? BrJ Psychiatry 2002; 180

483-4.

18 Abdelmawla N, Mitchell AJ. Sudden cardiac death and antipsychotics. Part 2: Monitoring and prevention. Adv Psychiatr Treat 2006; 12 $100-9$.

19 Haddad PM, Sharma SG. Adverse effects of atypical antipsychotics: differential risk and clinical implications. CNS Drugs 2007; 21 911-36.

20 Gill SS, Rochon PA, Herrmann N, Philip EL, Sykora K, Gunraj N, et al. Atypical antipsychotic drugs and risk of ischaemic stroke: population based retrospective cohort study. BMI2005: 330: 445

21 NHS Connecting for Health. NHS Care Record Service. NHS, 2005.

22 Brennan S. The NHS IT Project: The Biggest Computer Project in the World Ever. Radcliffe Publishing, 2005.

23 Association of the British Pharmaceutical Industry (ABPI): ABPI Medicines Compendium.
Datapharm Communications, 2006 (http://www.emc.medicines. org.uk).

24 British Medical Association, Roya Pharmaceutical Society of Great Britain. British National Formulary 51. BMA, 2006

25 David T, Paton C, Kerwin R. The Maudsley 2005-2006 Prescribing Guidelines (8th edn). Taylor and Francis, 2005.

26 Lebovitz HE. Metabolic consequences of atypical antipsychotic drugs. Psychiatr $Q$ 2003; 74: 277-90.

27 Antai-Otong D. Metabolic effects associated with atypical antipsychotic medications. Perspect Psychiatr Care 2004; 40 $70-2$.

28 American Diabetes Association, American Psychiatric Association, American Association of Clinical Endocrinologists, North American Association for the Study of Obesity. Consensus development conference on antipsychotic drugs and obesity and diabetes. Diabetes Care 2004: 27: 596-601

29 Medicines Control Agency, Committee on Safety of Medicines. QT interval prolongation with antipsychotics. Curr Probl Pharmacovigilance 2001; 27: 4

30 Royal College of Psychiatrists. Consensus Statement on HighDoseAntipsychotic Medication (R138). Royal College of Psychiatrists, 2006

31 Maguire GA. Prolactin elevation with antipsychotic medications: mechanisms of action and clinical consequences. J Clin Psychiatry 2002; 63 (suppl 4): 56-62.

32 DayJC,Wood G, Dewey M, Bentall RP. A self-rating scale for measuring neuroleptic side-effects. Validation in a group of schizophrenic patients. BrJ Psychiatry 1995; 166 $650-3$.

33 Rowlands P. The NICE schizophrenia guidelines: the challenge of implementation. Adv PsychiatrTreat 2004; 10: 403-12

Samantha Churchward Forensic Services Pharmacist, Devon Partnership NHS Trust, Langdon Hospital, Devon, Susan M. Oxborrow Staff Grade Psychiatrist, Bluebird House, Southampton, *Victor O. Olotu Staff Grade Psychiatrist, Langdon Hospital, Exeter Road, Dawlish, Devon, email: victor.olotu @nhs.uk, M. DeepakThalitaya Specialist Trainee Registrar, Brooklands Hospital, Brian Oliver Centre, Birmingham

\title{
Survey of Scottish psychiatrists' views on neuropsychology training
}

\author{
AIMS AND METHOD \\ A national survey of members of \\ the Scottish division of the Royal \\ College of Psychiatrists to \\ establish the training in \\ neuropsychology they have \\ received, their views on \\ neuropsychology service provision \\ and on potential formal \\ postgraduate neuropsychology \\ training opportunities.
}

\author{
RESULTS \\ A $54 \%(n=288)$ consultant \\ psychiatrist response rate was \\ achieved. The responses suggest that \\ where specialist neuropsychology \\ services exist, they are not perceived \\ to be sufficient to deal with clinical \\ demand. Consultant psychiatrists \\ indicated that there are limited \\ training opportunities in neuro- \\ psychology for psychiatrists, and this \\ seems to be reflected in their limited
}

confidence in interpreting basic recommended neuropsychological assessment tools. There seems to be a definite desire among consultant psychiatrists for postgraduate training opportunities.

\section{CLINICAL IMPLICATIONS}

Scottish psychiatrists desire an increase in formal neuropsychology training opportunities.
The application of neuropsychology is relevant to the majority of psychiatric subspecialties. This is affirmed in various national clinical guidelines: old age psychiatry in relation to the neurodegenerative disorders ${ }^{1-3}$ as well as psychiatry of learning disability and child and adolescent psychiatry in relation to the neurodevelopmental conditions that are clinically eloquent early in life. ${ }^{4-8}$ Specialists in general adult psychiatry and forensic psychiatry may encounter individuals affected with the aforementioned conditions. ${ }^{9}$ They also treat people with severe and enduring mental illness with neuropsychological sequelae, particularly the chronic psychotic disorders. It is important to distinguish the latter from other neurodegenerative condition, especially in senescence. ${ }^{10}$ The neuropsychological assessment of those with suspected alcohol-related brain damage is 
imperative in their diagnosis and treatment by the various relevant specialties, particularly liaison psychiatry and psychiatry of substance misuse. ${ }^{10,11}$

The Scottish Intercollegiate Guidelines Network (SIGN) guideline 86, Management of Patients with Dementia, ${ }^{2}$ recommends that neuropsychological testing should be used in the diagnosis of dementia, especially in individuals where dementia is not clinically obvious. The guideline acknowledges that the provision of neuropsychology services is variable and in some places nonexistent, suggesting psychiatrists often have to perform neuropsychological assessments by default. Postgraduate specialist psychiatric training courses appear to offer only rudimentary formal neuropsychology training to career psychiatric trainees. The only postgraduate neuropsychology training course in Scotland is offered by Glasgow University, but only clinical psychologists are eligible to enrol for training beyond a limited set of continuing professional development (CPD) modules.

\section{Method}

A questionnaire was designed to establish estimates of neuropsychology service provision, the level of neuropsychology training psychiatrists have received, and to elicit their views on formal postgraduate neuro-

psychology training (the questionnaire is available in full from the author).

At the time of the survey, the Scottish division of the Royal College of Psychiatrists had 1063 members. The Registrar supplied the contact details of the actively practising members who had consented to their details being made available. Questionnaires were posted in winter 2007 and a reminder was sent to nonrespondents. Data were managed and analysed with the assistance of the NHS Forth Valley Clinical Effectiveness Support Service.

\section{Results}

A total of 658 surveys were despatched and a $61.39 \%$ $(n=404)$ response rate was achieved. Overall, 288 consultants responded to this questionnaire, which equates to $71 \%$ of the total number of questionnaires returned. At the time of the survey, 538 consultants were working in Scotland, resulting in a consultant response rate of $54 \%$. As there was a relatively low response rate from non-consultant grades, it was decided to analyse the responses of consultants within their stated subspecialties (Appendix). Ninety-five per cent $(n=276)$ of consultants indicated that they have at least achieved MRCPsych level as their postgraduate psychiatric qualification. Training had been completed in its entirety in Scotland for $77 \%(n=222)$ of the participants, $8.5 \%$ $(n=25)$ partially in Scotland and $12.5 \%(n=36)$ completed their full training in other parts of the UK.

With regard to neuropsychology service provision in health board areas, 32\% $(n=99)$ of consultants indicated that a consultant neuropsychologist and 34\% $(n=99)$ that a psychologist with specialist interest in neuropsychology was available, and $13 \%(n=36)$ had access to both; $14 \%(n=40)$ indicated there was no service provision within their health board area, which included $12.5 \%(n=9)$ of old age psychiatrists. Table 1 illustrates by the consultants' subspecialty their rating of the sufficiency of the neuropsychology service available to them to deal with clinical demand.

Table 2 indicates that consultant old age psychiatrists have the highest level of confidence in using and interpreting common neuropsychological assessment tools (e.g. the Addenbrooke's Cognitive Examination recommended in SIGN 86), although only $62 \%$ of them indicated their level of confidence as 'good' or 'very good'. The consultants' in other subspecialties fairly average or low confidence in their basic clinical neuropsychological skills could be related to $5.5 \%(n=15)$ of consultants rating the availability of training in neuropsychology for psychiatrists as good to very good, 15.5\% $(n=45)$ as 'fair' and $73.5 \%(n=212)$ as 'poor' or 'very poor'.

A total of $35 \%(n=101)$ of consultant psychiatrists stated they had received training in neuropsychology, $4 \%$ ( $n=11$ ) indicated that the method of training was through participation in research. Of these respondents, $56.5 \%$ rated the value of this training in terms of their role as a psychiatrist as 'good' or 'very good', $30.5 \%$ as 'fair' and only $6 \%$ as 'poor' or 'very poor'. However, $49.5 \%$ of these consultants $(n=50)$, indicated that the method (or one of the methods) of their training in neuropsychology was self-directed.

Figure 1 illustrates the perceived value that consultants of all subspecialties hold for different levels of

Table 1. Consultants' rating of the sufficiency of the neuropsychology service available to them to deal with clinical demand

\begin{tabular}{|c|c|c|c|c|c|c|c|c|}
\hline & $\begin{array}{l}\text { General } \\
\text { adult } \\
(n=78)\end{array}$ & $\begin{array}{l}\text { Old age } \\
(n=52)\end{array}$ & $\begin{array}{l}\text { Liaison } \\
(n=12)\end{array}$ & $\begin{array}{c}\text { Forensic } \\
(n=16)\end{array}$ & $\begin{array}{l}\text { Rehabili- } \\
\text { tation } \\
(n=10)\end{array}$ & $\begin{array}{l}\text { Child and } \\
\text { adolescent } \\
(n=31)\end{array}$ & $\begin{array}{l}\text { Learning } \\
\text { disability } \\
(n=11)\end{array}$ & $\begin{array}{c}\text { Addiction } \\
\quad(n=7)\end{array}$ \\
\hline Very good & $2.5(2)$ & $23(12)$ & $8(1)$ & $6(1)$ & 0 & $3(1)$ & 0 & 0 \\
\hline Fair & $29.5(23)$ & $19(10)$ & $33(4)$ & $44(7)$ & $20(2)$ & $39(12)$ & $55(6)$ & $14(1)$ \\
\hline Poor & $23(18)$ & $29(15)$ & $25(3)$ & $25(4)$ & $10(1)$ & $10(3)$ & 0 & $43(3)$ \\
\hline Very poor & $4(3)$ & $4(2)$ & $25(3)$ & 0 & $10(1)$ & $19(6)$ & 0 & $14(1)$ \\
\hline Spoiled & $20.5(16)$ & $12(6)$ & 0 & $12.5(2)$ & $60(6)$ & $6(2)$ & $27(3)$ & $29(2)$ \\
\hline
\end{tabular}


Table 2. Consultants' level of confidence in using and interpreting common neuropsychological assessment tools

original papers

\begin{tabular}{|c|c|c|c|c|c|c|c|c|}
\hline & \multicolumn{8}{|c|}{$\%, n$} \\
\hline & $\begin{array}{c}\text { General } \\
\text { adult } \\
(n=102)\end{array}$ & $\begin{array}{l}\text { Old age } \\
(n=63)\end{array}$ & $\begin{array}{l}\text { Liaison } \\
(n=15)\end{array}$ & $\begin{array}{l}\text { Forensic } \\
(n=22)\end{array}$ & $\begin{array}{l}\text { Rehabili- } \\
\text { tation } \\
(n=12)\end{array}$ & $\begin{array}{l}\text { Child and } \\
\text { adolescent } \\
(n=34)\end{array}$ & $\begin{array}{l}\text { Learning } \\
\text { disability } \\
(n=15)\end{array}$ & $\begin{array}{c}\text { Addiction } \\
\quad(n=9)\end{array}$ \\
\hline Very good & $2(2)$ & $24(15)$ & $20(3)$ & $9(2)$ & 0 & 0 & 0 & $11(1)$ \\
\hline Poor & $44(45)$ & $13(8)$ & $20(3)$ & $32(7)$ & $42(5)$ & $35(12)$ & $33(5)$ & $56(5)$ \\
\hline Very poor & $10(10)$ & 0 & $7(1)$ & $9(2)$ & 0 & $32(11)$ & $20(3)$ & $22(2)$ \\
\hline Unanswered/spoiled & $3(3)$ & 0 & $7(1)$ & $9(2)$ & $8(1)$ & $9(3)$ & $20(3)$ & 0 \\
\hline
\end{tabular}

formal and accredited neuropsychology training for psychiatrists.

Of the $74 \%(n=212)$ of consultants who rated the availability of neuropsychology training for psychiatrists as 'poor' or 'very poor', 93\% (197) indicated that access to CPD modules would be of value and $47 \%$ (99) indicated the opportunity of postgraduate diploma or masters level training as valuable. Of the 182 consultants who stated they had no training in neuropsychology, $75 \%(n=158)$ regarded CPD modules as potentially valuable and $37 \%$ $(n=79)$ potential postgraduate diploma or masters level training as valuable. Within subspecialties, all 15 liaison psychiatrists, $92 \%$ of old age psychiatrists $(n=58)$ and $90 \%$ of general adult psychiatrists $(n=92)$ indicated that CPD modules would be of value. In addition, $74 \%(n=11)$ of the liaison psychiatrists and $67 \%(n=42)$ of the old age psychiatrists indicated that postgraduate diplomalevel training would be of value. In total, $66 \%(n=6)$ of addictions psychiatrists, $50 \%(n=17)$ of child and adolescent psychiatrists and 38\% $(n=24)$ of old age psychiatrists suggested masters degree training would be valuable.

At the end of the questionnaire an 'other comments' box was provided. There were three distinct themes of responses (from all 404 respondents). Twenty

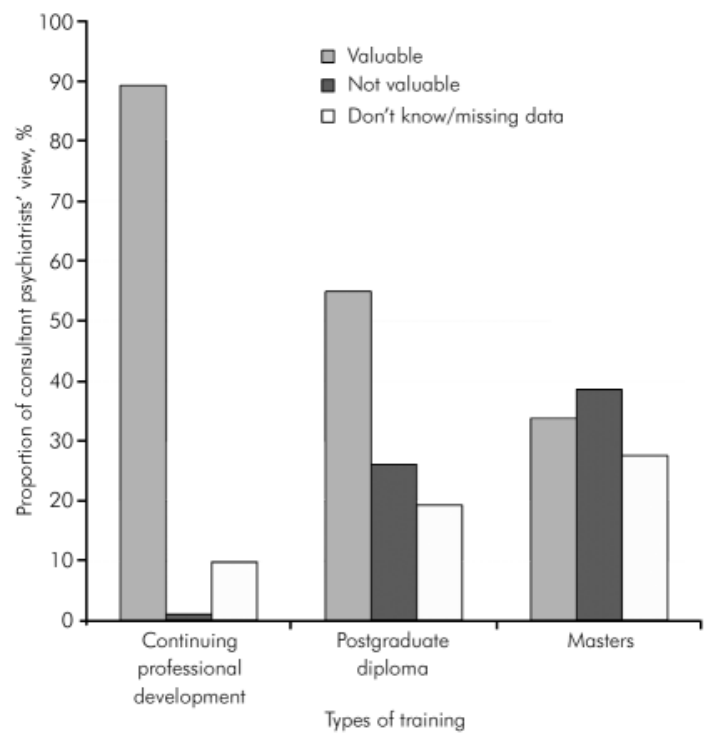

Fig. 1. Perceived value that consultants hold for different levels of potential neuropsychology training. respondents commented that they would not be interested in additional training in neuropsychology, as they did not view neuropsychological assessment as part of their clinical work. However, 63 respondents used the opportunity to express a desire to have access to further training. Twenty-six respondents used the 'other comments' box to express their frustrations at the dearth of neuropsychological service provision.

\section{Discussion}

The rationale for psychiatrists having training and knowledge in neuropsychology is endorsed and recommended by national and Royal College of Psychiatrists clinical guidelines, national integrated care pathways and by the Mental Welfare Commission for Scotland. This survey of Scottish consultant psychiatrists suggests that where specialist neuropsychology services exist, they are not perceived to be sufficient to deal with clinical demand. Consultant psychiatrists indicated that there are limited training opportunities in neuropsychology for psychiatrists and this seems reflected in their limited confidence in interpreting basic recommended neuropsychological assessment tools. There is a definite desire among consultant psychiatrists for postgraduate training opportunities, mostly for CPD modules, although various consultants of relevant subspecialties indicated that training at postgraduate diploma and masters' degree level would be valuable. The authors share the recommendations made by the Mental Welfare Commission for Scotland that 'Medical Directors of the Health Boards must ensure that all psychiatrists dealing with patients over the age of 18 are competent in the assessment and diagnosis of the full range of dementias they may encounter' and their final recommendation that 'all organisations providing medical education in mental health (Royal College of Psychiatrists, the Postgraduate Medical Education and Training Board and NHS Education Scotland)... should ensure that educational programmes address the issues of diagnosis, cognitive testing and the attitudes we have identified'. ${ }^{9}$ Clinical guidelines and the results of this survey affirm that these recommendations should be relevant to all subspecialties of psychiatry. Tertiary educational institutions should consider broadening the access of formal neuropsychology training to psychiatrists. 


\section{Declaration of interest}

None.

\section{Appendix}

Consultant respondents ( $n=288$ ) per subspecialty (of which seven had 'split posts' involving two subspecialties)

General adult and community psychiatry . . . . . . . . 102

Psychiatry of old age . . . . . . . . . . . . 63

Liaison psychiatry . . . . . . . . . . . . . . . . . . 15

Forensic mental health. . . . . . . . . . . . . . . . . . 22

Rehabilitation . . . . . . . . . . . . . . . . 12

Child and adolescent psychiatry . . . . . . . . . . 34

Learning disability . . . . . . . . . . . . . . . . . . . . . 15

Addictions . . . . . . . . . . . . . . . . . . . 9

Other. . . . . . . . . . . . . . . . . . . . . . 9

Unanswered/spoiled . . . . . . . . . . . . . . . . . . . . 14

\section{References}

1 Royal College of Psychiatrists. Forgetful but Not Forgotten: Assessment and Aspects of Treatment of People with Dementia by a Specialist Old Age Psychiatry Service (Council Report CR119). Royal College of Psychiatrists,

2005.
2 Scottish Intercollegiate Guidelines Network. Management of Patients with Dementia (SIGN86). SIGN, 2006 .

3 NHS Quality Improvement Scotland. Integrated Care Pathways for Mental: Bipolar
Disorder, Borderline Personality

Disorder, Dementia,

Depression, Schizophrenia. NHS Quality Improvement Scotland, 2007.

4 Royal College of Psychiatrists. Psychiatric Services for Children and Adolescents with Learning Disabilities (Council Report CR123). Royal College of Psychiatrists, 2004

5 Royal College of Psychiatrists. Meeting the Mental Health Needs of Adults with a Mild Learning Disability (Council Report CR115). Royal College of Psychiatrists, 2003.

6 Royal College of Psychiatrists. Psychiatric Services for Adolescents and Adults with Asperger Syndrome and Other AutisticSpectrum Disorders ( Council Report CR136). Royal College of sychiatrists, 2006.

7 Scottish Intercollegiate Guidelines Network. Assessment, Diagnosis and Clinical Interventions for Children and Young People with Autism Spectrum Disorders. A
National Clinical Guideline SIGN98). SIGN, 2007.

8 National Collaborating Centre for Mental Health. Attention Deficit Hyperactivity Disorder. Diagnosis and Management of ADHD in Children, Young People and Adults. National Clinical Practice Guideline Number 72. British Psychological Society \& Royal College of Psychiatrists, 2008.

9 Mental Welfare Commission for Scotland. Not my Problem, Report of the Inquiry into Deficiencies in the Care and Treatment of Mr Mental Welfare Commission for Scotland, 2007.

10 Royal College of Psychiatrists. Links not Boundaries: ServiceTransitions for People Growing Older with Enduring or Relapsing Mental Illness (Council Report CR153). Royal College of Psychiatrists, 2009

11 Dementia Services Development Services. A Fuller Life. Report of the Expert Group on Alcohol Related Brain Damage. Scottish Executive, 2004.

\section{LISA CONLAN, HELEN READ AND ELIZABETH PICTON}

\section{Taking the temperature: attitudes of patients on an all-female psychiatric ward to staff gender}

\section{AIMS AND METHOD}

To survey the attitudes of in-patients on an all-female ward to staff gender. All patients were invited to complete an anonymous questionnaire which was then repeated on a four-weekly basis for 4 months. Staff members were surveyed once within this period.

\section{RESULTS}

Only $15 \%$ of patients $(n=52)$ wanted all staff members to be female, whereas $87 \%$ reported feeling comfortable with male staff; $51 \%$ would prefer a predominantly female, mixed-gender staff. All staff $(n=11)$ were in favour of mixed-gender staffing.

\begin{abstract}
CLINICAL IMPLICATIONS
Current best practice for staffing single-gender acute in-patient units is unclear. This survey is in line with findings from other studies in that a large majority of female in-patients prefer to be in a unit with mixed staff.
\end{abstract}

original papers
In April 2006, Alex House Ground Floor Ward at the Bethlem Royal Hospital was converted from a mixedgender to an all-female in-patient unit but retained its mixed-gender staff. There has been ongoing debate surrounding the issue of staff gender. Should an acute female in-patient psychiatric unit be staffed by women alone?

In 2002, the Department of Health released a report entitled Women's Mental Health: Into the Mainstream., ${ }^{1,2}$
It focused on the main issues facing psychiatric care for women and suggested that a single-gender unit (staff gender not specified) should be an option for women, stressing their right to choice.

There is very little published data on this subject. In a study by Hingley \& Goodwin, $48 \%$ of women preferred mixed-gender in-patient accommodation. ${ }^{3}$ A further study by Batcup found that only $19 \%$ of the sampled in-patients wanted a single-gender environment, ${ }^{4}$ 